\title{
Treatment of chronic hepatitis $B$ in sub-Saharan Africa: 1-year results of a pilot program in Ethiopia
}

\author{
Hailemichael Desalegn ${ }^{1}$, Hanna Aberra', Nega Berhe ${ }^{2,3}$, Bitsatab Mekasha' ${ }^{1}$, Kathrine Stene-Johansen ${ }^{4}$,
} Henrik Krarup ${ }^{5}$, Andre Puntervold Pereira ${ }^{6}$, Svein Gunnar Gundersen ${ }^{7,8}$ and Asgeir Johannessen ${ }^{3, *^{*}}$ (D)

\begin{abstract}
Background: The World Health Organization has set an ambitious goal of eliminating viral hepatitis as a major public health threat by 2030. However, in sub-Saharan Africa, antiviral treatment of chronic hepatitis B (CHB) is virtually unavailable. Herein, we present the 1-year results of a pilot CHB treatment program in Ethiopia.
\end{abstract}

Methods: At a public hospital in Addis Ababa, CHB patients were treated with tenofovir disoproxil fumarate based on simplified eligibility criteria. Baseline assessment included liver function tests, viral markers, and transient elastography (Fibroscan). Changes in laboratory markers were analyzed using Wilcoxon signed-rank tests. Adherence to therapy was measured by pharmacy refill data.

Results: Out of 1303 patients, 328 (25.2\%) fulfilled the treatment criteria and 254 (19.5\%) had started tenofovir disoproxil fumarate therapy prior to September 1, 2016. Of the patients who started therapy, $30(11.8 \%)$ died within the first year of follow-up (28 of whom had decompensated cirrhosis), 9 (3.5\%) self-stopped treatment, 7 (2.8\%) were lost to follow-up, and 4 (1.6\%) were transferred out. In patients who completed 12 months of treatment, the median Fibroscan value declined from 12.8 to $10.4 \mathrm{kPa}(p<0.001)$, 172 of 202 (85.1\%) patients with available pharmacy refill data had taken $\geq 95 \%$ of their tablets, and 161 of 189 (85.2\%) patients with viral load results had suppressed viremia. Virologic failure $(\geq 69 \mathrm{IU} / \mathrm{mL})$ at 12 months was associated with high baseline HBV viral load $(>1,000,000 \mathrm{IU} / \mathrm{mL}$; adjusted OR $2.41 ; 95 \% \mathrm{Cl} 1.04-5.55)$ and suboptimal adherence (<95\%; adjusted OR 3.43, 95\% Cl 1.33-8.88).

Conclusions: This pilot program demonstrated that antiviral therapy of $\mathrm{CHB}$ can be realized in Ethiopia with good clinical and virologic response. Early mortality was high in patients with decompensated cirrhosis, underscoring the need for earlier detection of hepatitis B virus infection and timely initiation of treatment, prior to the development of irreversible complications, in sub-Saharan Africa.

Trial registration: NCT02344498 (ClinicalTrials.gov identifier). Registered 16 January 2015.

Keywords: Viral hepatitis, Antiviral therapy, Resource-limited settings, Epidemiology

\footnotetext{
* Correspondence: johannessen.asgeir@gmail.com

${ }^{3}$ Centre for Imported and Tropical Diseases, Oslo University Hospital, Ullevål,

PO Box 4956 Nydalen, 0424 Oslo, Norway

${ }^{9}$ Department of Infectious Diseases, Vestfold Hospital Trust, Tønsberg, Norway

Full list of author information is available at the end of the article
}

(c) The Author(s). 2018 Open Access This article is distributed under the terms of the Creative Commons Attribution 4.0 International License (http://creativecommons.org/licenses/by/4.0/), which permits unrestricted use, distribution, and reproduction in any medium, provided you give appropriate credit to the original author(s) and the source, provide a link to the Creative Commons license, and indicate if changes were made. The Creative Commons Public Domain Dedication waiver (http://creativecommons.org/publicdomain/zero/1.0/) applies to the data made available in this article, unless otherwise stated. 


\section{Background}

Chronic infection with hepatitis $\mathrm{B}$ virus (HBV) is a leading cause of cirrhosis, hepatic decompensation, and hepatocellular carcinoma (HCC). Approximately 257 million people worldwide are living with chronic hepatitis $\mathrm{B}(\mathrm{CHB})$, and an estimated 887,000 deaths per year are attributable to HBV infection [1]. Despite an effective vaccine and potent antiviral drugs, the number of HBV-related deaths has increased by $33 \%$ between 1990 and 2013 [2]. Indeed, in 2015, viral hepatitis claimed more lives than human immunodeficiency virus (HIV) [3].

Studies from high-income countries have shown that antiviral treatment of $\mathrm{CHB}$ reduces the risk of disease progression [4]. Long-term antiviral treatment has been shown to stop and even reverse liver fibrosis and prevent development of $\mathrm{HCC}[5,6]$. Hepatitis $\mathrm{B}$ surface antigen (HBsAg) loss is the optimal treatment endpoint, but is rarely achieved; thus, most patients need long-term treatment to suppress viral replication and prevent hepatic complications [7].

In sub-Saharan Africa, treatment for viral hepatitis is rarely available in the public sector. Patients with $\mathrm{CHB}$ are left untreated and physicians are left to merely follow the natural course of the disease and provide palliative care. Paradoxically, the recommended first-line drug for $\mathrm{CHB}$, tenofovir disoproxil fumarate (TDF), is registered in most African countries for the treatment of HIV, but not for hepatitis. Therefore, patients mono-infected with HBV cannot access life-saving treatment, whereas those with HIV/ HBV co-infection receive free treatment through donor agencies.

In 2016, the World Health Organization (WHO) published the Global Health Sector Strategy of Viral Hepatitis [3] and set an ambitious goal of eliminating viral hepatitis as a public health threat by 2030. To meet the WHO goals, countries and regions should reduce new infection by $90 \%$ and deaths by $65 \%$ by $2030[3,8]$. However, to date, few African countries have developed national action plans for viral hepatitis, and only one published study - the PROLIFICA study in The Gambia [9] - has reported results of HBV treatment on the continent. Consequently, there is a lack of local data to direct guidelines and promote implementation.

Herein, we present results from one of the first and largest public treatment programs for hepatitis B in sub-Saharan Africa. Many of the barriers to treatment in Ethiopia, such as lack of diagnostic facilities, absence of public funding, and restrictions on antiviral drugs, are shared by most low-income countries; therefore, we believe that our findings can be relevant in the global scaling-up of antiviral treatment of CHB.

\section{Methods}

\section{Study setting and participants}

Ethiopia is a low-income country in East Africa with an estimated prevalence of hepatitis B at 7.4\% [10]. A pilot program for the treatment of $\mathrm{CHB}$ was established in February 2015 at St. Paul's Hospital Millennium Medical College, which is a referral hospital in the capital Addis Ababa. A simplified approach to treatment and care of individuals with $\mathrm{CHB}$ was employed, wherein transient elastography rather than liver biopsy was used to assess liver fibrosis, nurses rather than physicians were responsible for most of the patient consultations, and treatment eligibility criteria were straight-forward and easy to use.

As this was the first public healthcare facility offering $\mathrm{CHB}$ treatment in the country, patients were referred from various hospitals, health centers, blood banks, and antenatal clinics for evaluation and treatment. Patients aged 18 years or above with $\mathrm{CHB}$, defined as a persistently positive HBsAg test for more than 6 months, were enrolled in the program. Since previous HBsAg testing was usually performed in other hospitals or private clinics, and often years back, we accepted the patients' recollection of a previous positive result without demanding a written laboratory report. Patients who were HIV positive at presentation were not included, but rather transferred to the nearest HIV care and treatment center. Likewise, individuals with a known terminal disease such as HCC were referred for further management elsewhere.

\section{Patient assessment and laboratory tests}

At enrollment, all patients were interviewed by a trained nurse in their own language. A full diagnostic work-up was performed, including laboratory tests and transient elastography. The following laboratory tests were performed at the first visit:

- Point-of-care rapid diagnostic tests: HBsAg, HIV (further tests were not performed in patients found to be HBsAg negative or HIV positive)

- Routine chemistry: complete blood count, bilirubin, alanine aminotransferase (ALT), aspartate aminotransferase (AST), creatinine

- Serology: HBsAg, hepatitis C virus (HCV) antibody, hepatitis D virus (HDV) antibody

- HBV DNA viral load

Patients with signs or symptoms of decompensated liver disease, such as ascites or jaundice, were scheduled to see a physician within 1-2 weeks. These patients would usually receive symptom-directed therapy such as diuretics for ascites/edema; however, within our simplified setup, we did not systematically perform endoscopic 
treatment of esophageal varices or other more advanced procedures.

Patients without signs or symptoms of advanced liver disease were appointed to a physician after 3 months when the viral load result would usually be available. The decision to start therapy was made by a physician using the predefined criteria given below; otherwise, the follow-up was nurse led.

Those who started antiviral therapy were followed-up after 2 and 4 weeks, and thereafter 3-monthly. The main focus at each visit was adherence counseling (including pill count) and monitoring for side effects. Untreated individuals were followed-up at 3-month intervals.

The following laboratory tests were performed during follow-up (tests in parenthesis were only performed in patients on treatment):

- 3-monthly: complete blood count, ALT, AST, (creatinine, HIV rapid test)

- 6-monthly: HBsAg, HBV viral load

Blood tests were performed using commercially available kits and assays. HBsAg was detected on-site using a WHO-approved rapid diagnostic test (Determine, Alere Inc., USA). HIV testing was done in accordance with the National algorithm, i.e., using a WHO-approved rapid test kit (HIV 1+2 Antibody Colloidal Gold [KHB], Shanghai Kehua Bio-engineering co., China) for screening, and another rapid test kit (HIV 1/2 STAT-PAK, Chembio Diagnostics, USA) for confirmation. Other routine laboratory investigations for hematology (HumaCount 30, Human, Germany), biochemistry (Humalyzer 3000, Human, Germany), and serology (Elisys Uno, Human, Germany) were performed locally.

Aspartate aminotransferase to platelet ratio index (APRI) and FIB-4 were derived from standard blood test results using the following formulas:

$$
\begin{aligned}
& \text { APRI : }(\text { AST }[\mathrm{U} / \mathrm{L}] / \text { upper limit of normal for AST }) \\
& / \text { platelet count }\left(10^{9} / \mathrm{L}\right) \times 100 \\
& \text { FIB-4 }:(\text { age }[\text { years }] \times \text { AST }[\mathrm{U} / \mathrm{L}]) / \\
& \left(\text { platelet count }\left[10^{9} / \mathrm{L}\right] \times(\text { ALT }[\mathrm{U} / \mathrm{L}])^{1 / 2}\right)
\end{aligned}
$$

HBV viral load testing was unavailable in Ethiopia at the time the program was set up; thus, baseline viral load testing was performed after shipment of samples to the Norwegian Public Health Institute (Oslo, Norway). The Abbott RealTime HBV assay (Abbott Molecular, Des Moines, USA) was used, following the manufacturer's instructions. From 2016, HBV viral load testing was established at a private laboratory in Addis Ababa using the Abbott RealTime HBV assay and therefore all follow-up samples for HBV viral load monitoring were tested locally.

HDV antibodies were detected using an enzyme-linked immunosorbent assay (ELISA) method (ETI-AB-DEL TAK-2, Diasorin, Italy) from EDTA plasma samples. A second anti-HDV ELISA assay (Dia.Pro Diagnostic Bioprobes Srl, Milan, Italy) was used to confirm indeterminate or weak positive results obtained with the Diasorin assay, as suggested by the manufacturer when plasma is used instead of serum. These analyses were performed at the Centre national de référence des hépatites $B, C$ et Delta, Hôpitaux universitaires de Paris-Seine-Saint-Denis, France.

\section{Liver fibrosis assessment}

Liver fibrosis was assessed using transient elastography (Fibroscan 402, Echosense, France). Patients were instructed to fast for at least $2 \mathrm{~h}$ prior to the examination, and the procedure was performed by an experienced operator as per the manufacturer's instructions. The median of 10 readings was employed, and the result was discarded if the interquartile range (IQR) divided by the median exceeded $30 \%$.

Based on a previous meta-analysis and a study from West Africa [11, 12], we used a Fibroscan threshold of $7.9 \mathrm{kPa}$ to define significant fibrosis (corresponding to Metavir score $\geq \mathrm{F} 2$ ) and $9.9 \mathrm{kPa}$ to define cirrhosis (corresponding to Metavir score F4). Ultrasound of the liver was performed at baseline, and thereafter annually, in all patients who started treatment, mainly to detect HCC.

\section{Treatment eligibility}

Since this program opened prior to the launch of the WHO Hepatitis B Guidelines in 2015 [13], treatment eligibility criteria were based on the European Association for the Study of the Liver (EASL) Guidelines from 2012 [7], with some modifications. Specifically, since liver biopsy was unrealistic in this setting, the two EASL criteria pertaining to liver inflammation (Metavir $\geq \mathrm{A} 2$ with viral load $>2000 \mathrm{IU} / \mathrm{mL}$ and ALT $>80 \mathrm{U} / \mathrm{L}$ with viral load $>20,000 \mathrm{IU} / \mathrm{mL}$ ) were merged into one, namely ALT $>80 \mathrm{U} / \mathrm{L}$ with viral load $>2000 \mathrm{IU} / \mathrm{mL}$. Furthermore, since African patients with $\mathrm{CHB}$ are at particular risk of $\mathrm{HCC}$, we created a new criterion for patients with HCC in their close family.

Thus, patients who fulfilled the following criteria were considered eligible for treatment:

1) Decompensated cirrhosis

2) Compensated cirrhosis (confirmed with ultrasound and/or Fibroscan)

3) Significant fibrosis (Fibroscan $>7.9 \mathrm{kPa}$ ) and viral load $>2000 \mathrm{IU} / \mathrm{mL}$

4) Moderate/severe liver inflammation (ALT $>80 \mathrm{U} / \mathrm{L}$ ) and viral load $>2000 \mathrm{IU} / \mathrm{mL}$ 
5) HCC among first-degree relatives and viral load $>2000 \mathrm{IU} / \mathrm{mL}$

Patients who met the treatment criteria were given adherence counseling and educated about the disease and the need for life-long follow-up. Preventive measures were recommended, including HBV vaccination to the patients' partner and children. Based on its potency, safety profile, and high barrier to resistance, TDF (Viread, Gilead Sciences, lnc., Foster City, CA, USA) 300 mg once daily was used in this program. Treatment for HCV and HDV co-infections were not available through this program.

\section{Assessment of adherence to therapy}

In patients who started antiviral treatment, TDF was initially dispensed for 1 month's duration, and thereafter at 3-monthly intervals. At each visit to the clinic, the patients were told to bring their old pill boxes so that the remaining pills could be counted. Adherence was calculated by dividing the total amount of tablets dispensed by the total number of days since initiating therapy, expressed as percentage. This method ('pharmacy refill' or 'pill count') has previously been proven accurate in HIV programs in resource-limited settings [14].

\section{Statistical analysis}

Baseline characteristics were summarized using descriptive statistics. Groups were compared using $X^{2}$ tests for categorical and Mann-Whitney U-tests for continuous variables. Changes over time in levels of ALT, viral load, and transient elastography were compared using Wilcoxon signed-rank tests. Intra-individual changes in Fibroscan measurements of more than $20 \%$ were considered significant [15].

Logistic regression models were used to study associations between baseline variables and clinically relevant outcomes (adherence, virologic failure, death). Variables with a $p$ value below 0.2 in univariable analyses were included in multivariable logistic regression models, using a forward stepwise method. HBV viral load $<69 \mathrm{IU} / \mathrm{mL}$ was considered as viral suppression to allow comparison with previous $\mathrm{CHB}$ studies $[6,16]$, and $>1000 \mathrm{IU} / \mathrm{mL}$ was considered as major virologic failure.

SPSS version 23.0 software (SPSS Inc., Chicago, IL, USA) was used to analyze the data. The level of significance was set at $p<0.05$. Results were reported in accordance with the Strengthening the Reporting of Observational studies in Epidemiology (STROBE) statement guidelines [17].

\section{Ethics}

The study was approved by the National Research Ethics Review Committee (Ref. No.: 3.10/829/07) in
Ethiopia and by the Regional Committees for Medical and Health Research Ethics (Ref. No.: 2014/1146) in Norway. The study was conducted in accordance with the Declaration of Helsinki. Written informed consent was obtained from all study subjects.

\section{Results \\ Patient characteristics}

Between February 9 and December 14, 2015, a total of 1303 adults with $\mathrm{CHB}$ were enrolled in the program. Of these, $328(25.2 \%)$ fulfilled the treatment criteria and $254(19.5 \%)$ started treatment prior to September 1, 2016 (Fig. 1). Compared to those who were ineligible for treatment, individuals who met the treatment eligibility criteria were more likely to be men, older, anti-HDV positive, and to have elevated ALT, high viral load and increased liver stiffness (Table 1). Patients eligible for treatment but who did not start it were more likely to have a normal liver stiffness $(<8.0 \mathrm{kPa}, 28.6$ vs. $10.5 \%$, $p<0.001$ ) and a lower APRI score (median 0.31 vs. 0.54 , $p=0.013$ ) compared to those who started treatment; other distinguishing features could not be identified.

Among those who started treatment, 197 (77.6\%) were men and the median age was 35 years (IQR 27-42). The majority $(n=137,53.9 \%)$ were from the capital city, Addis Ababa. The median ALT at baseline was $36 \mathrm{U} / \mathrm{L}$ (IQR 24-50), the median viral load was $26,700 \mathrm{IU} / \mathrm{mL}$ (IQR 568-9,480,000), and the median Fibroscan value was $15.5 \mathrm{kPa}$ (IQR 9.0-28.9).

\section{Antiviral treatment}

Most patients in this cohort started treatment based on a diagnosis of cirrhosis. A total of 105 (41.3\%) patients had clinical ascites or a history of ascites and were classified as decompensated cirrhosis, whereas 81 (31.9\%) patients without ascites had a Fibroscan value above $9.9 \mathrm{kPa}$ and were classified as compensated cirrhosis. The remaining started treatment based on significant liver fibrosis $(n=30,11.8 \%)$, moderate/severe liver inflammation $(n=14,5.5 \%), \mathrm{HCC}$ in a first-degree relative $(n=3,1.2 \%)$, or other criteria $(n=21,8.3 \%)$. The latter groups mainly comprised patients who had initiated treatment through the private sector or 'black market', and who could not be assessed using the standard criteria, since most of had suppressed viral load at enrollment.

Among patients who initiated treatment, 111 (43.7\%) started immediately (i.e., within 4 weeks of enrollment), mainly due to decompensated cirrhosis, whereas 116 (45.7\%) started treatment between 1 and 6 months of enrollment. Only 27 (10.6\%) started later than 6 months after enrollment. 


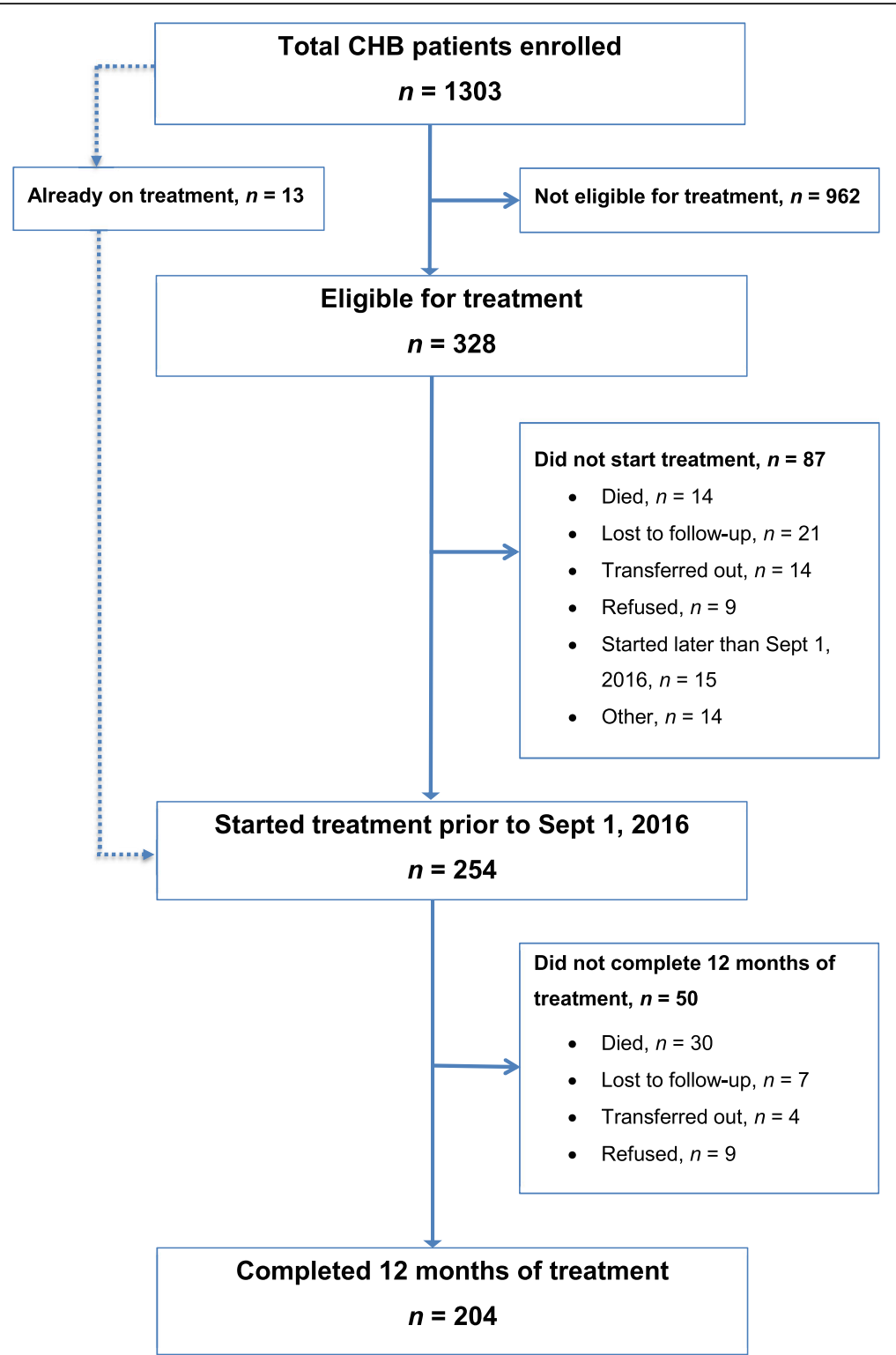

Fig. 1 Profile of the hepatitis B treatment program, Addis Ababa, Ethiopia. CHB chronic hepatitis B

\section{Treatment response}

Overall, 30 (11.8\%) patients died within the first 12 months after starting antiviral treatment, 28 of whom had decompensated cirrhosis at baseline. Among the decompensated patients, neither sex (men vs. women; odds ratio (OR) 1.54, 95\% confidence interval (CI) 0.40-5.91, $p=0.531$ ), age (per 1-year increment; OR 1.01, 95\% CI $0.97-1.06, p=0.549$ ), nor co-infections ( $\mathrm{HCV}$ and/or HDV; OR 1.11, 95\% CI 0.20-6.06, $p=0.906)$ predicted subsequent death.

Another 20 (7.9\%) patients failed to complete 12 months of TDF therapy; 7 (2.8\%) were lost to follow-up, $9(3.5 \%)$ refused to continue treatment for various reasons, and $4(1.6 \%)$ were transferred out. In the latter group, 3 were diagnosed with HCC and transferred to palliative care, and 1 was diagnosed with HIV on her 3-month follow-up visit and transferred to HIV care. Baseline characteristics of the 3 patients who developed HCC are summarized in Table 2.

Among the remaining 204 patients who completed 1 year of antiviral treatment, the median ALT was $36 \mathrm{U} / \mathrm{L}$ (IQR 24-47) at baseline and 32 U/L (IQR 24-39) at 12 months $(p=0.062)$, and the median Fibroscan value was $12.8 \mathrm{kPa}$ (IQR $8.8-23.6$ ) at baseline and $10.4 \mathrm{kPa}$ (IQR 6.8-17.4) at 12 months $(p<0.001)$. A total of 140 patients had paired Fibroscan results at baseline and 12 months for comparison; the median intra-individual improvement in liver stiffness at 12 months was $3.4 \mathrm{kPa}$ 
Table 1 Baseline characteristics of patients enrolled in a pilot treatment program for chronic hepatitis B, Addis Ababa, Ethiopia

\begin{tabular}{|c|c|c|c|c|}
\hline & $\begin{array}{l}\text { All patients } \\
(n=1303)\end{array}$ & $\begin{array}{l}\text { Eligible for treatment } \\
(n=328)\end{array}$ & $\begin{array}{l}\text { Not eligible for treatment } \\
(n=962)^{\mathrm{a}}\end{array}$ & \\
\hline & Number (\%) & Number (\%) & Number (\%) & $P$ \\
\hline$\overline{M e n}$ & $770(59.1)$ & $260(79.3)$ & $500(52.0)$ & $<0.001$ \\
\hline Age (years) & & & & 0.006 \\
\hline $18-25$ & $286(21.9)$ & $64(19.5)$ & $220(22.9)$ & \\
\hline $26-35$ & $549(42.1)$ & $122(37.2)$ & $424(44.1)$ & \\
\hline $36-45$ & $289(22.2)$ & $83(25.3)$ & $202(21.0)$ & \\
\hline$>45$ & $179(13.7)$ & $59(18.0)$ & $116(12.1)$ & \\
\hline Marital status & & & & 0.667 \\
\hline Single & $457(35.1)$ & $117(35.7)$ & $338(35.1)$ & \\
\hline Married & $796(61.1)$ & $201(61.3)$ & $584(60.7)$ & \\
\hline Divorced/widowed & $50(3.8)$ & $10(3.0)$ & $40(4.2)$ & \\
\hline$A L T, U / L^{b}$ & & & & $<0.001$ \\
\hline$<40$ & $1014(78.9)$ & $185(57.3)$ & $818(86.2)$ & \\
\hline $40-79$ & $201(15.6)$ & $91(28.2)$ & $108(11.4)$ & \\
\hline$\geq 80$ & $70(5.4)$ & 47 (14.6) & $23(2.4)$ & \\
\hline HBV viral load, IU/mL & & & & $<0.001$ \\
\hline$<2000$ & $722(56.5)$ & $107(33.1)$ & $608(64.5)$ & \\
\hline 2000-19,999 & $256(20.0)$ & $46(14.2)$ & $208(22.1)$ & \\
\hline$\geq 20,000$ & $301(23.5)$ & $170(52.6)$ & $127(13.5)$ & \\
\hline Transient elastography, $\mathrm{kPa}^{\mathrm{d}}$ & & & & $<0.001$ \\
\hline$<8.0$ & $879(74.0)$ & $46(15.0)$ & $825(94.5)$ & \\
\hline $8.0-9.9$ & $67(5.6)$ & $39(12.7)$ & $27(3.1)$ & \\
\hline$\geq 10.0$ & $242(20.4)$ & $221(72.2)$ & $21(2.4)$ & \\
\hline \multicolumn{5}{|l|}{ Co-infections } \\
\hline Anti-HCV positive & $28(2.1)$ & $7(3.2)$ & $21(2.6)$ & 0.619 \\
\hline Anti-HDV positive & $19(1.4)$ & $10(5.9)$ & $9(1.0)$ & $<0.001$ \\
\hline APRI, median $(\mid \mathrm{QR})^{\mathrm{e}}$ & $0.24(0.17-0.36)$ & $0.48(0.27-0.90)$ & $0.21(0.16-0.29)$ & $<0.001$ \\
\hline FIB-4, median $(\mid \mathrm{QR})^{\mathrm{f}}$ & $0.56(0.41-0.79)$ & $1.06(0.61-1.91)$ & $0.55(0.41-0.76)$ & $<0.001$ \\
\hline
\end{tabular}

$A L T$ alanine aminotransferase, $H B V$ hepatitis B virus, $H C V$ hepatitis $C$ virus, $H D V$ hepatitis D virus, $A P R I$ aspartate aminotransferase to platelet ratio index, IQR interquartile range

${ }^{\mathrm{a}} 13$ patients were already on treatment and could not be assessed for treatment eligibility

${ }^{\mathrm{b}} 18$ results missing

c 24 results missing

${ }^{\mathrm{d}} 111$ results missing

e 124 results missing

${ }^{f} 128$ results missing

(IQR 0.4-7.0) (Fig. 2). After 12 months of treatment, 83 (59.3\%) patients had a significant improvement in liver stiffness, 41 (29.3\%) were unchanged $(<20 \%$ change from baseline), and $16(11.4 \%)$ deteriorated.

Five individuals (2.5\%) experienced HBsAg loss, i.e., they had two consecutively negative HBsAg results; 4 of these developed anti-HBs antibodies. In retrospect, however, 2 cases might have been acute hepatitis B since HBsAg positivity 6 months prior to inclusion could not be documented.

Out of 189 patients who had a viral load test performed at 12 months, 161 (85.2\%) had suppressed viremia (i.e., $<69 \mathrm{IU} / \mathrm{mL}$ ) and only 6 (3.2\%) had major virologic failure (i.e., $>1000 \mathrm{IU} / \mathrm{mL}$ ). Genotypic resistance testing was performed in these 6 samples; 3 had wild type virus and 3 failed amplification due to low viral loads. The proportion of patients with suppressed viremia at 6 and 12 months is given in Fig. 3. Virologic failure (i.e., $\geq 69 \mathrm{IU} / \mathrm{mL}$ ) at 12 months was associated with high baseline HBV viral load (>1,000,000 IU/mL) and suboptimal adherence $(<95 \%)$ (Table 3$)$.

TDF therapy was generally well tolerated and only one individual with underlying comorbidities (diabetes mellitus, hypertension, gout, cardiomyopathy, alcohol abuse) 
Table 2 Characteristics of patients who developed hepatocellular carcinoma during the initial 12 months of antiviral treatment

\begin{tabular}{llll}
\hline Baseline characteristics & Patient 1 & Patient 2 & Patient 3 \\
\hline Sex & $\mathrm{F}$ & $\mathrm{M}$ & $\mathrm{M}$ \\
Age & 65 & 55 & 50 \\
ALT, U/L & 81 & 30 & 110 \\
HBV viral load, IU/mL & 75 & 13 & 10,100 \\
Transient elastography, kPa & 29.0 & 20.6 & 75.0 \\
Co-infection (HCV/HDV) & No & No & HDV \\
Co-morbidity & No & IDDM & IDDM \\
Previous antiviral therapy & No & No & No \\
Decompensated liver disease & No & Yes & Yes \\
\hline
\end{tabular}

$A L T$ alanine aminotransferase, $H B V$ hepatitis $B$ virus, $H C V$ hepatitis $C$ virus, $H D V$ hepatitis $D$ virus, IDDM insulin-dependent diabetes mellitus

discontinued due to progressive worsening of renal function. This patient was under treatment with several drugs, including diuretics and an angiotensin-converting enzyme inhibitor, and the role of TDF in the development of renal failure remains unclear.

\section{Adherence}

Pharmacy refill data was available for 202 out of 204 patients who completed 12 months of antiviral treatment. Out of these, 172 (85.1\%) individuals had excellent adherence, i.e., they took more than $95 \%$ of their tablets; 24 (11.9\%) had medium adherence, i.e., they took between 80 and $95 \%$ of their tablets; and 6 had poor adherence, i.e., they took less than $80 \%$ of their tablets. Neither sex (men vs. women; OR 1.67, 95\% CI 0.60-4.62, $p=0.326$ ), age (per 1-year increment; OR 0.98, 95\% CI 0.94-1.02, $p=0.221$ ), nor decompensated liver disease (OR 1.11,
95\% CI 0.20-6.06, $p=0.906$ ) were significantly associated with suboptimal adherence (i.e., $<95 \%$ ).

\section{Discussion}

This report summarizes 1-year treatment results from the largest published cohort of $\mathrm{CHB}$ patients in sub-Saharan Africa. The findings indicate that antiviral treatment can be delivered safely and effectively in a low-income setting like Ethiopia using a simplified approach, similar to the early experiences from HIV treatment programs on the continent. In our own setup, the day-to-day management of patients, including the initial patient interview, liver stiffness measurement, blood testing and patient education, was performed by trained nurses, whereas physicians were involved only in the actual decision to start therapy and in the management of complications. Such task shifting, from physicians to trained nurses, has been successful in HIV programs throughout Africa [18], and may also prove useful in the management of other chronic infections like CHB.

The estimated 1-year mortality among patients who started treatment was $11.8 \%$. The high early mortality likely reflects the absence of treatment options for $\mathrm{CHB}$ in the country to date; thus, patients with advanced cirrhosis, who are desperate for treatment, might have been overrepresented in our cohort. Indeed, 28 of 30 patients who died had decompensated cirrhosis at enrollment. On the other hand, approximately three-quarters of patients with decompensated cirrhosis in our study were still alive after 12 months of TDF treatment. These results are in line with a study from Korea [19], where 1-year transplantation-free survival was of $87.1 \%$ among 70 patients with decompensated cirrhosis treated with entecavir, suggesting that treatment of this group is safe and

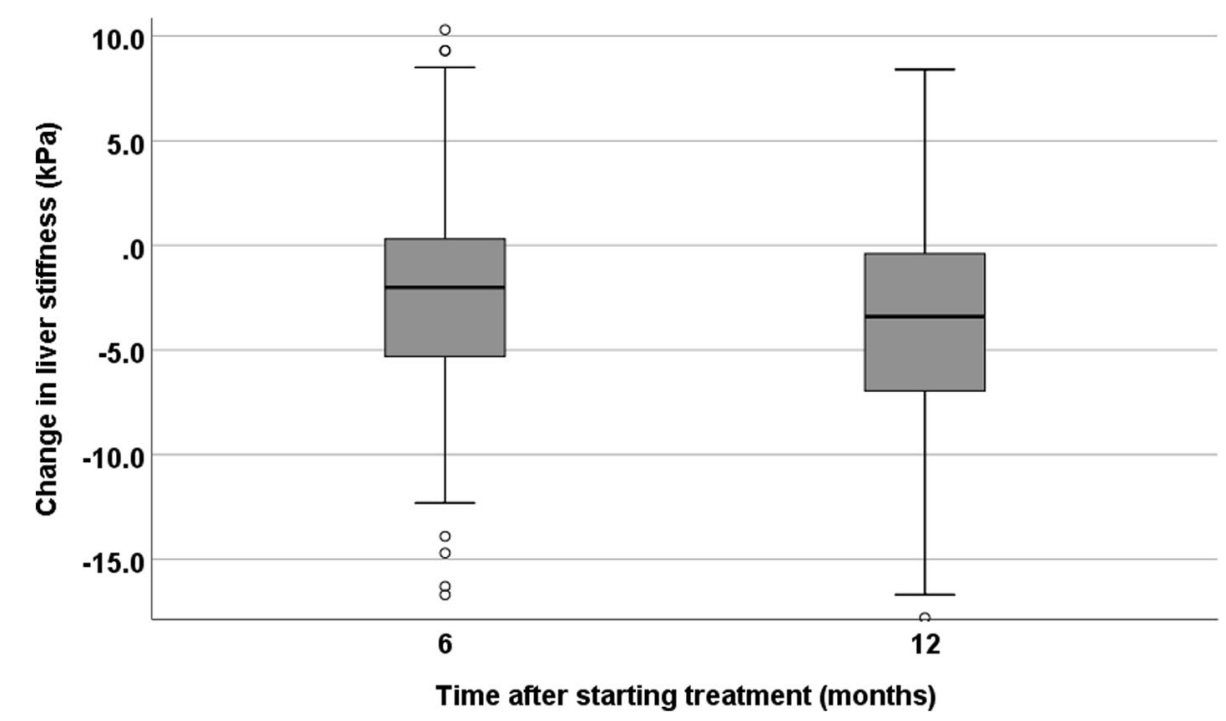

Fig. 2 Change in liver stiffness among patients who completed 12 months of hepatitis B treatment 




Fig. 3 Virologic response to therapy during the first 12 months of antiviral treatment

beneficial. Clearly, however, a major challenge in the Ethiopian setting is the identification of HBV-infected individuals earlier in the course of their illness, prior to the development of severe complications. This would require better access to HBV testing and screening, and improved access to antiviral therapy throughout the country.

In our study, $85.2 \%$ of patients achieved viral suppression 12 months after treatment initiation. Only 6 patients had major virologic failure and no genotypic resistance was discovered. This is comparable to studies from high-income settings. Indeed, in the phase 3 study of TDF supported by Gilead Sciences, viral suppression below 69
$\mathrm{IU} / \mathrm{mL}$ was achieved in $76 \%$ and $93 \%$ of $\mathrm{HBeAg}$-positive and HBeAg-negative patients, respectively [16]. Moreover, in a real-life multicenter study of $302 \mathrm{CHB}$ patients from 19 countries in Europe, 68\% of HBeAg-positive patients and $90 \%$ HBeAg-negative patients treated with TDF had a suppressed viral load after 12 months [20]. Studies from low- and middle-income countries are scarce, but in a retrospective study involving 220 cirrhotic patients from India [21], 91.8\% had suppressed viremia after 12 months treatment with TDF. Furthermore, in a large real-life study from 50 sites in China [22], viral suppression after 12 months treatment with entecavir was achieved in $64 \%$ of patients with compensated liver disease and $68 \%$ with decompensated liver disease. Of note, detectable viremia at 12 months does not necessarily imply treatment failure, since it might take longer than 12 months to achieve full viral suppression in individuals with very high baseline viral loads [20].

Interestingly, liver stiffness (measured by Fibroscan) improved significantly during the initial 12 months of therapy. Reversal of liver fibrosis during antiviral therapy has previously been described by Marcellin et al. [6], who reported a significant improvement in fibrosis scores in repeated liver biopsies after 1 and 5 years of TDF treatment. Whether histological improvement translates to reduced risk of HCC and death has yet to be proven in Africa, but experiences from other settings indicate that antiviral treatment significantly reduces the risk of these complications [5].

The program loss in the present study was relatively low; overall, $6.3 \%$ were lost to follow-up or self-stopped

Table 3 Predictors of virologic failure (HBV viral load $\geq 69 \mathrm{lU} / \mathrm{mL}$ ) after 12 months of antiviral treatment, Addis Ababa, Ethiopia

\begin{tabular}{|c|c|c|c|c|c|c|}
\hline \multirow[t]{2}{*}{ Baseline variable } & \multirow{2}{*}{$\begin{array}{l}\text { Total }(n=189) \\
n(\%)\end{array}$} & \multirow{2}{*}{$\begin{array}{l}\text { Virologic failure }(n=28) \\
n(\%)\end{array}$} & \multicolumn{2}{|l|}{ Crude } & \multicolumn{2}{|l|}{ Adjusted } \\
\hline & & & OR $(95 \% \mathrm{Cl})$ & $p$ & OR $(95 \% \mathrm{Cl})$ & $p$ \\
\hline \multicolumn{7}{|l|}{ Sex } \\
\hline Women & $44(23.3)$ & $5(17.9)$ & 1 & & & \\
\hline Men & $145(76.7)$ & $23(82.1)$ & $1.52(0.54-4.26)$ & 0.426 & & \\
\hline Age, years (per 1-year increment) & $35(26-41)^{a}$ & $35(26-41)^{a}$ & $1.00(0.96-1.04)$ & 0.952 & & \\
\hline \multicolumn{7}{|l|}{ Decompensated liver disease } \\
\hline No & $126(66.7)$ & $20(71.4)$ & 1 & & & \\
\hline Yes & $63(33.3)$ & $8(28.6)$ & $0.77(0.32-1.86)$ & 0.563 & & \\
\hline \multicolumn{7}{|l|}{ HBV viral load, IU/mL ${ }^{b}$} \\
\hline$\leq 10^{6}$ & $116(62.0)$ & $12(42.9)$ & 1 & & 1 & \\
\hline$>10^{6}$ & $71(38.0)$ & $16(57.1)$ & $2.52(1.11-5.71)$ & 0.026 & $2.41(1.04-5.55)$ & 0.039 \\
\hline \multicolumn{7}{|l|}{ Adherence $^{c}$} \\
\hline$\geq 95 \%$ & $160(85.1)$ & $19(67.9)$ & 1 & & 1 & \\
\hline$<95 \%$ & $28(14.9)$ & $9(32.1)$ & 3.74 (1.47-9.49) & 0.006 & $3.43(1.33-8.88)$ & 0.011 \\
\hline
\end{tabular}

$H B V$ hepatitis $B$ virus, $O R$ odds ratio, $C l$ confidence interval

${ }^{a}$ Median (interquartile range)

${ }^{\mathrm{b}}$ Two missing values

'One missing value 
treatment. Although the follow-up time in our study was shorter, this drop-out rate was lower than results from a recent multicenter study in Germany involving 33 sites across the country [23], where $75 \%$ remained in the study after 36 months of TDF treatment. In the only previous publication of $\mathrm{CHB}$ treatment in sub-Saharan Africa [9], there was no program loss after 12 months; however, the numbers were small.

Adherence to therapy was high in this cohort; $85.1 \%$ of patients took at least $95 \%$ of their medication; this is in line with studies from high-income countries. In a study from USA [24], non-adherence was reported in 10-12\% of patients after 4 years of HBV therapy, whereas a study from France found non-adherence among $7 \%$ of patients after at least 3 months of CHB treatment [25]. High adherence is a prerequisite to achieve the clinical benefits of therapy and to avoid resistance; however, contrary to first-generation anti-HBV drugs, resistance does not seem to be a significant problem with TDF [26]. Previous studies from HIV programs have found that adherence rates in Africa are at least as good as in North America or Europe [27]; our study suggests that the same appears to be true for $\mathrm{CHB}$ treatment.

In the present program, treatment decisions were based on viral load testing and liver stiffness measurements. However, in most countries in sub-Saharan Africa, these tests are practically unavailable. Although the WHO recommends the initiation of treatment based on clinical and laboratory markers such as the APRI, experiences from our cohort shows that this marker fails to detect $90 \%$ of those in need of treatment [28]. Transient elastography, on the contrary, has shown excellent agreement with liver biopsy [29], and is non-invasive and easy to use, making it an appealing tool in resource-limited settings. Nevertheless, the retail price of a Fibroscan machine is currently beyond the budget of most low-income settings, for which generic competition or other financial mechanisms to improve access to this technology is an urgent priority.

With regard to viral load measurements, we have previously shown that dried blood spots can be used to reliably quantify HBV DNA [30], which means that samples can be sent to a central facility from smaller centers throughout the country. Additionally, the recent development of point-of-care molecular assays for various pathogens represent a new era of near-patient testing, and GeneXpert (Cepheid, Sunnyvale, CA, USA) is expected to launch their HBV DNA viral load kit later in 2018 (personal communication, Emiliano Leone, Cepheid). Improved access to low-cost, robust, point-of-care diagnostics will be a prerequisite to achieve the WHO goal of treating $80 \%$ of eligible persons with $\mathrm{CHB}$ within 2030 [3]. However, reaching this goal will also require concerted action from international stakeholders and local ministries of health to establish adequate funding mechanisms, develop local treatment guidelines, and remove legislative barriers to generic antiviral drugs.

Our study had certain limitations. First, although the treatment program was set up at a local public hospital, external financial support was provided to purchase a Fibroscan device and run viral load testing. Nevertheless, the clinic was run exclusively with local staff, most of whom had no previous experience with hepatitis B management, and we believe the setup can be duplicated in other countries in sub-Saharan Africa. Second, since this was the first treatment center for CHB in the country, patients with symptomatic (i.e., decompensated) liver disease were overrepresented. The high early mortality in the program reflects this, and as treatment becomes more accessible mortality can be expected to decline.

\section{Conclusion}

The current pilot study showed that treatment for $\mathrm{CHB}$ can be successful in terms of adherence to therapy and retention in care. Furthermore, there was significant improvement in liver stiffness during the initial 12 months of treatment, with the majority of patients achieving viral suppression. However, initial mortality was high, given that many patients presented with advanced cirrhosis. Therefore, earlier detection of HBV infection and timely initiation of treatment - prior to the development of irreversible complications - is needed to reach the WHO goal of eliminating viral hepatitis as a public health threat by 2030 . This pilot program can provide valuable information for other African countries aiming to expand access to antiviral treatment of $\mathrm{CHB}$.

\section{Abbreviations \\ ALT: alanine aminotransferase; APRI: aspartate aminotransferase to platelet ratio index; AST: aspartate aminotransferase; $\mathrm{CHB}$ : chronic hepatitis B; Cl: confidence interval; EASL: European Association for the Study of the Liver; HBsAg: hepatitis B surface antigen; HBV: hepatitis B virus; HCC: hepatocellular carcinoma; HCV: hepatitis C virus; HDV: hepatitis D virus; HIV: human immunodeficiency virus; IQR: interquartile range; OR: odds ratio; TDF: tenofovir disoproxil fumarate; WHO: World Health Organization}

\section{Acknowledgements}

We are indebted to the patients who participated in the study. We are thankful to the staff at the hepatitis clinic at St Paul's Hospital Millennium Medical College, as well as the laboratory staff at Aklilu Lemma Institute of Pathobiology and the Norwegian Institute of Public Health for their dedication and hard work.

\section{Funding}

This study was funded by The Norwegian Research Council, grant number 220622/H10, and the South-Eastern Norway Regional Health Authority, grant number 2011068. Antiviral drugs were donated by Gilead Sciences, Inc.,

Foster City, CA, USA. The sponsors had no role in the design, data collection, data analysis, data interpretation or writing of this paper, nor in the decision to submit the paper for publication.

\section{Availability of data and materials}

The datasets used and/or analyzed during the current study are available from the corresponding author on reasonable request. 


\section{Authors' contributions}

AJ conceived the study and wrote the protocol with significant contributions from NB and SGG. HD, HA, and BM were responsible for patient enrollment and data acquisition. KSJ and HK were responsible for the laboratory work and interpretation of results. APP collected adherence data and participated in data analysis. AJ and HD performed statistical analyses. AJ and HD drafted the manuscript, and all authors critically revised it and approved the final version.

\section{Ethics, consent and permissions}

The study was approved by the Regional Committee for Medical and Health Research Ethics in Norway and the National Research Ethics Review Committee in Ethiopia, as well as the pertinent institutional ethical review boards. Written informed consent was obtained from all study participants.

\section{Consent for publication}

Not applicable.

\section{Competing interests}

The authors declare that they have no competing interests.

\section{Publisher's Note}

Springer Nature remains neutral with regard to jurisdictional claims in published maps and institutional affiliations.

\section{Author details}

'Medical Department, St. Paul's Hospital Millennium Medical College, Addis Ababa, Ethiopia. ${ }^{2}$ Aklilu Lemma Institute of Pathobiology, Addis Ababa University, Addis Ababa, Ethiopia. ${ }^{3}$ Centre for Imported and Tropical Diseases, Oslo University Hospital, Ullevål, PO Box 4956 Nydalen, 0424 Oslo, Norway. ${ }^{4}$ Department of Molecular Biology, Norwegian Institute of Public Health, Oslo, Norway. ${ }^{5}$ Section of Molecular Diagnostics, Aalborg University Hospital, Aalborg, Denmark. ${ }^{6}$ Faculty of Medicine, University of Oslo, Oslo, Norway. ${ }^{7}$ Research Unit, Sørlandet Hospital HF, Kristiansand, Norway. ${ }^{8}$ Department of Global Development and Planning, University of Agder, Kristiansand, Norway. ${ }^{9}$ Department of Infectious Diseases, Vestfold Hospital Trust, Tønsberg, Norway.

Received: 23 May 2018 Accepted: 30 November 2018 Published online: 17 December 2018

\section{References}

1. World Health Organization. Hepatitis B Fact Sheet. Geneva: WHO; 2017. http:// www.who.int/mediacentre/factsheets/fs204/en/. Accessed 22 Feb 2018

2. Stanaway JD, Flaxman AD, Naghavi $M$, et al. The global burden of viral hepatitis from 1990 to 2013: findings from the global burden disease study 2013. Lancet 2016;388:1081-1088

3. World Health Organization. Global Health Sector Strategy on Viral Hepatitis. Towards Ending Viral Hepatitis. Geneva: WHO; 2016.

4. Liaw YF, Sung JJ, Chow WC, et al. Lamivudine for patients with chronic hepatitis B and advanced liver disease. N Engl J Med 2004;351:1521-1531.

5. Kim WR, Loomba R, Berg T, et al. Impact of long-term tenofovir disoproxil fumarate on incidence of hepatocellular carcinoma in patients with chronic hepatitis B. Cancer 2015;121:3631-3638.

6. Marcellin P, Gane E, Buti M. Regression of cirrhosis during treatment with tenofovir disoproxil fumarate for chronic hepatitis B: a 5-year open-label follow-up study. Lancet 2013;381:468-475.

7. European Association for the Study of the Liver. EASL Clinical Practice Guidelines: management of chronic hepatitis B virus infection. J Hepatol 2012:57:167-185.

8. World Health Organization. Global Hepatitis Report, 2017. Geneva: WHO; 2017.

9. Lemoine M, Shimakawa $Y$, Njie R, et al. Acceptability and feasibility of a screen-and-treat programme for hepatitis B virus infection in The Gambia: the Prevention of Liver Fibrosis and Cancer in Africa (PROLIFICA) study. Lancet Glob Health 2016:4:e559-e567.

10. Belyhun Y, Maier M, Mulu A, Diro E, Liebert UG. Hepatitis viruses in Ethiopia: a systematic review and meta-analysis. BMC Infect Dis 2016;16:761.

11. Chon YE, Choi EH, Song KJ, et al. Performance of transient elastography for the staging of liver fibrosis in patients with chronic hepatitis B: a metaanalysis. PLoS One 2012;7:e44930.

12. Lemoine $M$, Shimakawa $Y$, Nayagam $S$, et al. The gamma-glutamyl transpeptidase to platelet ratio (GPR) predicts significant liver fibrosis and cirrhosis in patients with chronic HBV infection in West Africa. Gut 2016;65: 1369-1376.

13. World Health Organization. Guidelines for the Prevention, Care and Treatment of Persons with Chronic Hepatitis B Infection. Geneva: WHO; 2015.

14. Sangeda RZ, Mosha F, Prosperi M, et al. Pharmacy refill adherence outperforms self-reported methods in predicting HIV therapy outcome in resource-limited settings. BMC Public Health 2014;14:1035.

15. Boursier J, Konate A, Gorea G, et al. Reproducibility of liver stiffness measurement by ultrasonographic elastometry. Clin Gastroenterol Hepatol 2008;6:1263-1269.

16. Marcellin P, Heathcote J, Buti M, et al. Tenofovir disoproxil fumarate versus adefovir dipivoxil for chronic hepatitis B. JAMA 2008;359:2442-2455.

17. von Elm E, Altman DG, Egger $M$, et al. The Strengthening the Reporting of Observational Studies in Epidemiology (STROBE) statement: guidelines for reporting observational studies. Lancet 2007:370:1453-1457.

18. Sanne I, Orrell C, Fox MP, et al. Nurse versus doctor management of HIVinfected patients receiving antiretroviral therapy (CIPRA-SA): a randomized non-inferiority trial. Lancet 2010;376:33-40.

19. Shim JH, Lee HC, Kim KM, et al. Efficacy of entecavir in treatment-naive patients with hepatitis B virus-related decompensated cirrhosis. J Hepatol 2010;52:176-182.

20. Pol S, Lampertico P. First-line treatment of chronic hepatitis B with entecavir or tenofovir in 'real-life' settings: from clinical trials to clinical practice. J Viral Hepat 2012;19:377-386.

21. Goyal SK, Dixit VK, Shukla SK, et al. Prolonged use of tenofovir and entecavir in hepatitis B virus-related cirrhosis. Indian J Gastroenterol 2015:34:286-291.

22. Hou $J$, Jia JD, Wei $L$, et al. Efficacy and safety of entecavir in a heterogenous CHB population from a 'real-world' clinical practice setting in China. J Viral Hepat 2013;20:811-820.

23. Petersen J, Heyne R, Mauss S, et al. Effectiveness and safety of tenofovir disoproxil fumarate in chronic hepatitis B: a 3-year prospective field practice study in Germany. Dig Dis Sci 2016;61:3061-3071.

24. Ha NB, Ha NB, Garcia RT, et al. Medication nonadherence with long-term management of patients with hepatitis B e-antigen negative chronic hepatitis B. Dig Dis Sci 2011;56:2423-2431.

25. Sogni $P$, Carrieri MP, Fontaine $H$, et al. The role of adherence in virological suppression in patients receiving anti-HBV analogues. Antivir Ther 2012;17:395-400.

26. Liu Y, Corsa AC, Buti M, et al. No detectable resistance to tenofovir disoproxil fumarate in $\mathrm{HBeAg}+$ and $\mathrm{HBeAg}$ - patients with chronic hepatitis $B$ after 8 years of treatment. J Viral Hepat 2017;24:68-74.

27. Mills EJ, Nachega JB, Buchan I, et al. Adherence to antiretroviral therapy in subSaharan Africa and North America: a meta-analysis. JAMA 2006;296:679-690.

28. Desalegn H, Aberra H, Berhe N, Gundersen SG, Johannessen A. Are noninvasive fibrosis markers for chronic hepatitis B valid in sub-Saharan Africa? Liver Int 2017;37:1461-1467.

29. Afdhal NH, Bacon BR, Patel K, et al. Accuracy of fibroscan, compared with histology, in analysis of liver fibrosis in patients with hepatitis B or C: a United States multicentre study. Clin Gastroenterol Hepatol 2015:13:772-779.

30. Stene-Johansen K, Yaqoob N, Øverbø J, et al. Dried blood spots a reliable method for measurement of HBV viral load in resource-limited settings. PLoS One 2016;11:e0166201.

Ready to submit your research? Choose BMC and benefit from

- fast, convenient online submission

- thorough peer review by experienced researchers in your field

- rapid publication on acceptance

- support for research data, including large and complex data types

- gold Open Access which fosters wider collaboration and increased citations

- maximum visibility for your research: over $100 \mathrm{M}$ website views per year

At BMC, research is always in progress.

Learn more biomedcentral.com/submission 